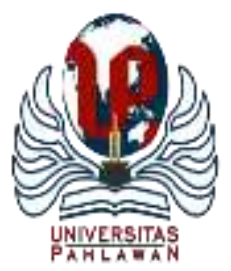

Edukatif : Jurnal Ilmu Pendidikan Volume 3 Nomor 6 Tahun 2021 Halm 4320 - 4328

EDUKATIF: JURNAL ILMU PENDIDIKAN

Research \& Learning in Education

https:/ledukatif.org/index.php/edukatif/index

\title{
Pengembangan Pendidikan Islam Berbasis Entrepreneur pada Pondok Pesantren Al Mumtaz Patuk
}

\author{
Fajrus Shodiq $^{1 凶}$, Nur Khusaini ${ }^{2}$, Bintang Muhammad Nur Ikhsan $^{3}$, Siti Halawatus Sa’diyah $^{4}$, \\ Aulia Faiqotul Himma ${ }^{5}$ \\ Universitas Islam Negeri Sunan Kalijaga Yogyakarta, Indonesia ${ }^{1,3,4,5}$ \\ Institut Ilmu AL-Qur'an An-Nur Yogyakarta, Indonesia² \\ E-mail : $\underline{\text { Surjafqidos@ gmail.com }}{ }^{1}$, nkhusaini786@ gmail.com $^{2}$, Bintangmuhammadnur@ gmail.com $^{3}$, \\ Halawatus@gmail.com ${ }^{4}$, auliafaiqotulhimma@ gmail.com ${ }^{5}$
}

\begin{abstract}
Abstrak
Al Mumtaz Patuk Gunung Kidul. Kedua, mengetahui upaya pengembangan pendidikan Islam berbasis entrepreneur pada pondok pesantren Al Mumtaz Patuk Gunung Kidul. Ketiga, mengetahui dampak dari pengembangan pendidikan Islam berbasis entrepreneur pada pondok pesantren Al Mumtaz Patuk Gunung Kidul. Jenis penelitian kualitatif. Pengumpulan data dilakukan dengan cara wawancara, observasi dan dokumentasi. analisis data menggunakan analisis interaktif yang dikembangkan oleh Miles dan Hubermen. Keabsahan data menggunakan triangulasi pengecekan data dari berbagai sumber dengan cara dan waktu. Hasil dari penilitian ini adalah: Pertama, pondok pesantren Al Mumtaz memadukan kurikulum dari kemenag dengan kurikulum pesantren dan entrepreneur. Kedua, pondok pesantren Al Mumtaz menggunakan metode pembentukan karakter, metode keteladanan dan metode pembiasaan serta metode praktik. Ketiga, pondok pesantren Al Mumtaz adalah memiliki keterampilan, menumbuhkan jiwa entrepreneur, menumbuhkan sikap mandiri, membantu kebutuhan pondok.
\end{abstract}

Kata kunci: pendidikan Islam, entrepreneur dan pondok pesantren

\begin{abstract}
This study aims: First, to find out the concept of the development of entrepreneurial-based Islamic education at the Al Mumtaz Patuk Gunung Kidul Islamic boarding school. Second, knowing the efforts to develop entrepreneurial-based Islamic education at the Al Mumtaz Patuk Gunung Kidul Islamic boarding school. Third, knowing the impact of the development of entrepreneurial-based Islamic education at the Al Mumtaz Patuk Gunung Kidul Islamic boarding school. Type of qualitative research. Data collection was carried out by means of interviews, observation and documentation. data analysis using interactive analysis developed by Miles and Hubermen. The validity of the data using triangulation checking data from various sources by means and time.The results of this research are: First, the Al Mumtaz Islamic boarding school combines the curriculum from the Ministry of Religion with the Islamic boarding school curriculum and entrepreneurship. Second, the Al Mumtaz Islamic boarding school uses character building methods, exemplary methods and habituation methods as well as practice methods. Third, the Al Mumtaz Islamic boarding school is having skills, fostering an entrepreneurial spirit, fostering an independent attitude, helping the needs of the boarding school.
\end{abstract}

Keywords: Islamic education, entrepreneurship and Islamic boarding school

Copyright (c) 2021 Fajrus Shodiq, Nur Khusaini, Bintang Muhammad Nur Ikhsan, Siti Halawatus Sa'diyah, Aulia Faiqotul Himma

$\triangle$ Corresponding author

Email : Surjafqidos@gmail.com

DOI : https://doi.org/10.31004/edukatif.v3i6.1447

ISSN 2656-8063 (Media Cetak)

ISSN 2656-8071 (Media Online)

Edukatif : Jurnal Ilmu Pendidikan Vol 3 No 6 Tahun 2021 p-ISSN 2656-8063 e-ISSN 2656-8071 
4321 Pengembangan Pendidikan Islam Berbasis Entrepreneur pada Pondok Pesantren Al Mumtaz PatukFajrus Shodiq, Nur Khusaini, Bintang Muhammad Nur Ikhsan,Siti Halawatus Sa'diyah, Aulia Faiqotul Himma

DOI: https://doi.org/10.31004/edukatif.v3i6.1447

\section{PENDAHULUAN}

Pendidikan merupakan investasi proses yang membutuhkan waktu lama untuk menyipakan peserta didik. Pendidikan ini telah diakui oleh bangsa-bangsa di dunia baik negara berkembang maupun negara maju. Demikian juga dengan negara Indonesia, juga menaruh harapan bagi pembangunan masa depan bangsa, karena pendidikan dibentuk untuk harapan anak muda bangsa sebagai generasi penurus bangsa. Pendidikan juga tidak terlepas dari kehidupan nyata di masa depan, yaitu kehidupan peserta didik. karena itu, pendidikan harus dirancang semaksimal mungkin untuk mempersipakan kehidupan yang lebih baik di masa depan, dan pada saat itu juga harus ditanamkan nilai-nilai agama yang dapat menjadi pondasi untuk kehidupan di masa mendatang (Qodry, 2004: 70)

Untuk mewujudkan fungsi pendidikan di atas, maka pendidikan Islam berperan penting dalam meningkatkan kualitas sumber daya manusia. Sesuai dengan karakteristik pendidikan agamanya memiliki fungsi yang ideal dalam penyiapan sumber daya manusia dalam pengetahuan dan karakter, sikap moral dalam pengalaman ajaran agama. Pendidikan Islam itu sendiri berfungsi membina dan menyiapkan anak didik yang berilmu, berteknologi, berketerampilan tinggi serta beramal sholeh (Akhidiyat, 2009:147)

Salah satu lembaga yang bernama "pesantren", itu sangat membantu membentuk kepribadian karakter seseorang, tidak hanya itu. Lembaga tertua yang ada di Indonesia salah satunya adalah "pesantren". Pesantren sendiri mempunyai keunikan pembelajaran tentang spiritual dan lembaga pembinaan moral. Dalam tatanan pendidikan nasional pondok pesantren ini adalah asli Indonesia, dan memiliki akar trasdisional yang sangat dalam di masyarakat Indonesia. Pesantren merupakan lembaga pendidikan Islam yang mempunyai peran sangat penting, antara lain: (1) sebagai pusat penyebaran ilmu ke Islaman. (2) sebagai pengawal dan pemelihara keberlangsungan tradisi Islam. (3) sebagai pusat penyebaran ilmu keislaman. Dengan adanya figur, seperti kyai/ulama pesantren telah berperan penting dalam pengetahuan dan intensifikasi Islam di masyarakat muslim nusantara (Masduki HS, 2002: 20)

Pendidikan pesantren dalam menciptakan peserta didik atau santri yang berkualitas tidak hanya diberi materi pelajaran agama tapi juga diberikan pendidikan entrepreneurship. Pendidikan entrepreneurship ini sangat penting dalam kehidupan dan pembangunan suatu negara. Pendidikan entrepreneurship ini harus ada di semua aspek pembelajaran. Rendahnya atau lemahnya pendidikan entrepreneurship membuat peserta didik sangat lambat dalam mengubah dinamikanya agar dapat beradaptasi dengan kemajuan, karena dalam pendidikan entrepreneurship peserta didik diberikan kemampuan pengembangan minat dan bakat.(Noor, 2006: 19)

Oleh sebab itu, pendidikan entrepreneurship di Indonesia masih kurang mendapat perhatian. Terutama para guru/pendidik yang tidak sepenuh memperhatikan pertumbuhan sikap dan perilaku anak didiknya di lingkungan sekolah maupun di lembaga pendidikan professional. Salah satu alternatif pendidikan entrepreneurship adalah pendidikan Islam berbasis entrepreneurship.

Dengan memperhatikan latar belakang di atas, Pondok Pesantren Al Mumtaz yang didirikan oleh KH. Mohamad Khoeron, S.Ag sebagai salah satu lembaga pendidikan Islam yang menciptakan peserta didik/santri berjiwa entrepreneurship. Pondok pesantren Al Mumtaz ini didirikan dengan dilandasi IT dan Entrepreneurship (Wirausaha), pada waktu merancang pembangunan dasar ini dilandasi dengan mengacu pada empat pilar, antara lain: (1) pendidikan agama yang kuat, (2) kemahiran berbahasa asing (bahasa Arab dan bahasa Inggris), (3) akhlaqul karimah, dan (4) kewirausahaan dan penguasaan IT (Ilmu Teknologi). Dengan adanya empat pilar ini alumni pondok pesantren Al Mumtaz mampu meningkatkan prestasinya dengan menjadi pengusaha yang sukses dengan berprinsip sesuai ajaran islam. Berani bersaing di tingkat lokal, nasional dan internasional dengan menguasai IT, serta mahir dalam berbahasa dan kemampuan aqidah Islamiyah yang tangguh (Hasil wawancara dengan Ade Rokoyah, 11 Juli 2019) 
4322 Pengembangan Pendidikan Islam Berbasis Entrepreneur pada Pondok Pesantren Al Mumtaz PatukFajrus Shodiq, Nur Khusaini, Bintang Muhammad Nur Ikhsan,Siti Halawatus Sa'diyah, Aulia Faiqotul Himma

DOI: https://doi.org/10.31004/edukatif.v3i6.1447

Pondok pesantren yang terletak Jl. Jogja-Wonosari, Kerjan, Beji, Patuk, Kabupaten Gunung Kidul ini selain mengajarkan agama juga mengajarkan cara produksi, pemasaran dan manajemen bisnis. Pada umumnya pondok pesantren yang memiliki kewirausahan hanya berwujud koperasi simpan pinjam, mini market dan toko kitab, berbeda dengan pondok pesantren Al Mumtaz ini yang telah memiliki banyak bidang kegiatan kewirausahaan seperti perikanan, pertanian, rest area, pembuatan sabun cuci, industri roti dll. Santri pondok pesantren Al Mumtaz ini juga memproduksi seragam santri bermotif batik Al Mumtaz yang merupakan kerja sama tim batik dan tim jahit. Motif batik ini merupakan hasil karya santri pondok pesantren Al Mumtaz yang sudah diluncurkan pada tahun 2018 dengan nama Batik Gaplek.

Pondok pesantren Al Mumtaz ini juga telah membuka wisata halal yaitu pasar tradisional Ahad Pahing yang melibatkan warga masyarakat sekitar. Pasar ini diresmikan langsung oleh Bupati $\mathrm{Hj}$. Badingah, S.Sos. dengan harapan dapat menjadi sumber rejeki yang halalan thayyiban, sesuai ajaran Islam dan mampu mendukung perkembangan wisata di Gunung Kidul (Hasil wawancara dengan Nandang Kuswandi, 11 Juli 2019). Letak pondok yang sangat strategis yaitu dijalan Wonosari ini mampu dimanfaatkan dengan membuka wisata halal tersebut. Kegiatan entrepreneurship yang banyak ini tidak lantas menghilangkan pendidikan agama Islam akan tetapi pondok pesantren Al Mumtaz ini mampu memadukan antara pendidikan agama Islam dengan entrepreneurship serta mampu memadukan kurikulum dari kemenag.

Ada beberapa penelitian yang mengungkap tentang "pengembangan pendidikan Islam berbasis Entrepreneur pada pondok pesantren Al Mumtaz patuk" Tetapi dalam penelusaran lapangan (field research) belum ditemukan penelitian yang menjelaskan tentang pengembangan pendidikan Islam berbasis entrepreneurship di pondok pesantren. Ada beberapa penelitian yang terkait dengan penelitain ini, antara lain: Pertama, penelitian dari Patmawati (2017). Kedua, penelitian dari Widiyanti (2012). Ketiga, penelitian dari Meilani (2017). Oleh sebab itu, peneliti tertarik untuk meneliti "Pengembangan pendidikan Islam berbasis Entrepreneur pada pondok pesantren Al Mumtaz Patuk".

\section{Pengertian Entrepreneuship}

Menurut Kementerian Pendidikan, kewirausahaan merupakan sikap, semangat, dan kemampuan untuk menciptakan hal-hal baru yang sangat berharga dan bermanfaat bagi diri sendiri maupun orang lain. Ilmuan seorang Joseph Schumpeter juga mengartikan entrepreneur atau entrepreneuship adalah orang yang mendobrak sistem ekonomi yang ada dengan memperkenalkan barang dan jasa yang baru, dengan menciptakan bentuk organisasi baru atau mengolah bahan baku baru (Alma, 2018: 24)

Dari penjelasan di atas dari ditarik kesimpualan bahwa kewirausahaan/entrepreneurship adalah suatu sikap yang mencerminkan karakter seseorang wirausahawan dapat menciptakan hal-hal yang baru yang berguna bagi dirinya atau orang disekelilingnya.

\section{Sifat Entrepreneuship}

Menurut Ali Hasan dalam bukunya Manajemen Bisnis Syari'ah,(Hasan, 2013: 123), mengungkapkan beberapa sifat karakteristik entrepreneuship, antara lain: (a) meiliki sifat tauhid, (b) percaya diri,(c) orientasi tugas dan hasil, (d) resiko dan tantangan, (e) kepimpinan,(f) orsinil,(g) orientasi.

\section{Kerangka Acuan Entrepreneur Islam}

\section{Al-Qur'an}

Al Qur'an sebagai landasan yang paling utama dalam pendidikan Islam dan entrepreneur dimana terdapat norma-norma umat Islam terdapat pada al Qur'an.(Beni Ahmad Saebani dan Hendra Ahdiyat, 2012: 63)

2. Sunnah Rosul 
4323 Pengembangan Pendidikan Islam Berbasis Entrepreneur pada Pondok Pesantren Al Mumtaz PatukFajrus Shodiq, Nur Khusaini, Bintang Muhammad Nur Ikhsan,Siti Halawatus Sa'diyah, Aulia Faiqotul Himma

DOI: https://doi.org/10.31004/edukatif.v3i6.1447

Pengimplementasian Al Qur'an tidak bisa serta merta mengabaikan adanya sunnah rasul apalagi mengingkarinya, tidak terkecuali dalam kaitannya tentang entrepreneur. Karena dalam ayat al Qur'an ini hanya memuat prinsip pokok dari semua ajara Islam baik berkenaan dengan ibadah murni seprti halnya shalat, haji, zakat, puasa dan lainnya, maupun ibadah umum seperti halnya muamalah, sosial, ekonomi dan lainnya. (Aziz, 2014: 49)

\section{Ijitihad}

Al Qur'an dan sunnah rasul tanpa adanya ijtihad tidak mudah untuk diimplementasikan dalam kehidupan. Oleh sebab itu dengan ijtihad akan mampu menggerakan program-program suatu organisasi apapun bentuknya organisasi itu, contohnya seperti entrepreneur, sosial, perdagangan, budaya dan sebagainya (Aziz, 2014)

\section{METODE PENELITIAN}

Kategori penelitian ini adalah penelitian lapangan (field research), yakni, sebuah penelitian yang bertujuan untuk melakukan penelitian mendalam tentang suatu unit-unit sosial dengan menghasilkan gambaran yang terorganisasi dengan lengkap mengenai unit sosial tersebut (Anwar, 1999: 3). Penelitian ini dilakukan secara terperinci dan mendalam mengenai pengembangan pendidikan Islam berbasis Entrepreneurship pada pondok pesantren Al Mumtaz Patuk Gunung Kidul.

Jenis penelitian ini merupakan penelitian kualitatif, artinya,penelitian ini bertujuan untuk mengetahui fenomena yang terjadi atau yang dialami oleh subjek penelitian, antara lain; perilaku, persepsi, motivasi, dan tindakan.(Moloeng, 2012: 6)

Sumber utama dari penelitian ini adalah subyek penelitian, yang berkaitan dengan data variabel-variabel yang diteliti (Moloeng, 2012). Subyek penelitian dapat berupa orang, benda atau hal-hal lain yang dapat dijadikan subyek penelitian. Adapun subyek penelitian ini adalah: Pertama, pengasuh Pondok Pesantren Al Mumtaz Patuk GunungKidul. Kedua, Uztadz/Guru Pondok Pesantren Al Mumtaz Patuk Gunung Kidul. Ketiga, Pengurus Pondok Pesantren Al Mumtaz Patuk Gunung Kidul. Keempat, sebagian para santri yang ikut terlibat dalam kegiatan tersebut.

Data yang dikumpulkan dengan cara observasi, wawancara, dan dokumentasi (Sugiyono, 2013: 137). Analisa data menggunakan analisis interaktif yang dikembangkan oleh Miles dan Huberman melalui tahaptahap sebagai berikut: Pertama, mereduksi data dengan cara mengumpulkan, merangkum, membuang data yang tidak perlu dan mefokuskan data yang sudah ada. Kedua, sajian data merupakan uraian dan penjelasan secara urut sehingga menggambarkan data secara keseluruhan sesuai dengan tujuan penelitian, untuk memudahkan memahami dan merencanakan kerja selanjutnya proses pengelompokan data-data untuk menyimpulkan data, yang kemudian dilakukan deskripsi yang berisi penjelasan tematik sesuai dengan hasil penemuan lapangan. Ketiga, penyimpulan data merupakan menyimpulkan data-data yang telah sesuai dengan objek penelitian dan melakukan pengecekan data-data lapangan untuk meneliti kembali kebenarannya. Sedangkan keabsahan data dalam penelitian ini menggunakan triangulasi, yaitu pengecekan data dari berbagai sumber dengan berbagai cara dan waktu. Dalam penelitian ini triangulasi yang digunakan adalah triangulasi sumber, yaitu; dengan membandingkan dan mengecek derajat kepercayaan informasi yang diperoleh melalui sumber yang beragam terkait satu sama lain.(Komariah, 2011: 170) 
4324 Pengembangan Pendidikan Islam Berbasis Entrepreneur pada Pondok Pesantren Al Mumtaz PatukFajrus Shodiq, Nur Khusaini, Bintang Muhammad Nur Ikhsan,Siti Halawatus Sa'diyah, Aulia Faiqotul Himma

DOI: https://doi.org/10.31004/edukatif.v3i6.1447

\title{
HASIL DAN PEMBAHASAN
}

Menurut Ahmad Tafsir mengungkapkan, pendidikan Islam merupakan landasan primer pembelajaran yang diberikan kepada seseorang untuk mengamalkan secara maksimal ajaran-ajaran Islam yang telah dituangkan dalam Al-Qur'an dan Hadits (Mohammad Daud Ali, 2016: 78). Pondok pesantren Al Mumtaz merupakan lembaga Islam, sudah pastinya proses belajar mengajarnya dengan baik keagamaan Islam dengan budaya pesantren yang sangat kental. Akan tetapi, memiliki perbedaan ajaran yang di jalankan pondok pesantren ini yaitu dengan ciri khas entrepreunernya. Terlepas dari perbedaan itu pondok pesantren ini patut diberikan apresiasi karena menerapkan ajaran pendidikan Islam dengan basis entrepreuner yang berhasil dan sesuai dengan cita-cita pengasuh pondok pesantren Al Mumtaz yaitu membantu pemerintah dalam membasmi kemiskinan.

Mengacu pada tujuan penelitian di atas, maka peneliti menyimpulkan hasil penelitian, antara lain:

\author{
Pengembangan pendidikan agama Islam berbasis entrepreuner pondok Pesantren Al Mumtaz Patuk, \\ antara lain: \\ a. Pengembangan SDM. \\ b. Pendidikan agama Islam entrepreuner \\ c. Pengembangan skill peserta didik \\ d. Meningkatkan spiritualisasi entrepreuner (Hasil wawancara dengan Muhammad Khoiron, 11 Agustus \\ 2020)
}

\section{Konsep pengembangan pendidikan Islam berbasis pada pondok Pesantren Al-Mumtaz Patuk, antara lain:}

a. Penerapan Kurikulum Entrepreunership, Kemenag dan Kemendiknas

Kurikulum pendidikan formal yang ada di pondok Pesantren Al-Mumtaz mengikuti kurikulum dari Kemenag maupun Kemendiknas. Selain kurikulum dari Kemenag dan Kemendiknas pondok Pesantren AlMumtaz juga mengkombinasikan dengan kurikulum pesantren yaitu entrepreneur.

Berdasarkan hasil wawancara peneliti dengan pengasuh pondok Pesantren Al Mumtaz bapak Muhammad Khoiron mengatakan:

"Untuk konsep pendidikan agama Islam yang kami jalankan di Pondok Pesantren ini pada umumnya sama dengan seperti pondok lainnya, di pondok ini ada pendidikan formal mulai dari RA sampai MA, sedangkan untuk kurikulum pendidikan formalnya kami menggunakan acuan kurikulum Kemenag dan Kemendiknas. Selain kurikulum dari Kemenag dan Kemendiknas kami tambahkan dengan kurikulum pesantren yaitu entrepreneur.(Hasil wawancara dengan Muhammad Khoiron, 11 Agustus 2020)

Konsep pendidikan Islam pada intinya untuk memajuhkan seluruh potensi peserta didik dengan semaksimal mungkin, baik yang menyangkut aspek jasmaniah, maupun rohaniah, akal dan akhlaq (Syaodih, 1996: 98). Pondok Pesantren Al Mumtaz merupakan pondok pesantren yang menerapkan kurikulum pendidikan entrepreuner. Kurikulum terintegrasi antara kurikulum pesantren, kurikulum Kemenag dan Kemendiknas. Model pembelajaran pondok Pesantren Al Mumtaz lebih mengutamakan pengembangan potensi santri atau peserta didik (Hasil wawancara dengan Muhammad Khoiron, 11 Agustus 2020)

"Konsep besarnya pengembangan Pendidikan Islam berbasis entrepreuner adalah membantu pemerintah memberantas kemiskinan, jangka panjangnya yaitu memperbaiki pendidikan, saya ngonsep sebelum mendirikan pesantren yaitu tahun 1997/1998, saat Indonesia mengalami krisis moneter'(Hasil wawancara dengan Muhammad Khoiron,11 Agustus 2020)

Kh Khoriron berpendapat bahwa kemiskinan itu di sebabkan bukan karena takdir, tapi karena sifat mental, di sebabkan mental males, miskin skill, kaya gengsi, dan komsumtif. Dalam menangani kasus yang 
4325 Pengembangan Pendidikan Islam Berbasis Entrepreneur pada Pondok Pesantren Al Mumtaz PatukFajrus Shodiq, Nur Khusaini, Bintang Muhammad Nur Ikhsan,Siti Halawatus Sa'diyah, Aulia Faiqotul Himma

DOI: https://doi.org/10.31004/edukatif.v3i6.1447

seperti ini sistem pendidikan Indonesia harus di rubah, bagaimana pendidikan ini harus membentuk karakter building, mengembangkan skill peserta didik, meningkatkan kreatifitas, dan inovasi (Observasi,19 Agustus 2020).

Kurikulum ini tidak sekedar membuat santri atau peserta didik mengerti apa yang di pelajari, akan tetapi lebih menekankan agar peserta didik dapat memecahkan suatu permasalahan dan menemukan cara-cara terbaru dalam melakukan kreasi, terobosan, dan berinovasi (Hasil dengan Muhammad Khoironwawancara,11 Agustus 2020)

Oleh sebab itu, kurikulum entrepreuner merupakan proses pembelajaran penanaman tata nilai kewirausahaan mengedepankan pembiasaan dan pemeliharaan perilaku serta sikap. Seorang wirausahawan harus memiliki sifat sebagai wirausahawan.

b. Praktik dalam KehidupanSehari-hari

Proses belajar mengajar, teori dan praktik bisa di katakan berhasil jika ada praktik yang dilakukan oleh peserta didik. Dalam hal ini Pengajar memberikan contoh terlebih dahulu terhadap peserta didik. Sama halnya dengan pondok pesantren yang lainnya, kegiatan santri di pondok Pesantren Al Mumtaz sholat berjama'ah dan mengaji, namun yang jadi pembeda dari pondok pesantren lainnya yaitu di sela-sela hari di ajarkan dengan berwirausaha (Observasi, 22 Juni 2020)

c. Membantu Masyarakat Memberantas Kemiskinan

Sejarah di bentuknya Pondok Pesantren Al Mumtaz diantaranya yaitu memiliki cita-cita membantu pemerintah untuk memberantas kemiskinan. Karena pada waktu pendirianya di tahun 1997/1998 Indonesia sedang mengalami krisis moneter. Perekonomian Indonesia yang sedang kacau, nilai rupiah anjlok, dan lain sebagainnya. Pondok Pesantren Al Mumtaz hadir di tengah-tengah krisis tersebut (Marthon, 2004: 142). Kurikulum pondok pesantren berbasis entrepreuner ini di dasar dengan adanya krisis moneter.

Semua wilayah termasuk Patuk Gunung Kidul mengalami krisis tersebut, keadaan ekonomi masyarakat Patuk Gunung Kidul pada masa itu cukup memprihatinkan. Pengasuh pondok pesantren melihat realita seperti itu pada akhirnya membangun sebuah pondok pesantren dengan ajaran kurikulum berbasis entrepreuner, agar masyarakat di kemudian hari mentalnya matang dalam menghadapi kejadian yang seperti itu.

Peneliti menyimpulkan dengan berdirinya pondok pesantren ini, dapat membantu pemerintah dalam memberantas kemiskinan, seperti adanya pasar ahad pahing, santunan santri dan keluarga miskin, serta memiliki program bakti sosial dengan kegiatannya yaitu belajar mengajar pada masyarakat terutama pada anak-anak yang tidak sempat mengenyam pendidikan. Jadi, tidak hanya membantu memberantas kemiskinan di sektor perekonomian saja, melainkan sektor pendidikan juga (Observasi, 21 Juli 2019)

\section{Upaya Pengembangan Pendidikan Agama Islam Dengan Basis Entrepreunership di Pondok Pesantren AlMumtaz}

Upaya merupakan salah satu usaha yang dijalankan oleh lembaga pendidikan untuk menerapkan tujuan yang telah di rumuskan. Pendidikan agama Islam berbasis entreprenership dapat menjawab tantangan perubahan zaman. Pendidikan dalam basis Entrepreuner lebih menguntungkan kepada peserta didik atau santri karena peserta didik digali potensinya yang kemudian dikembangkan potensi peserta didik (Hamali, 2017: 23)

Pengembangan pendidikan agama Islam basis Entrepreunership, nilai-nilai pendidikan agama Islam akan diterapkan dalam pembelajaran dengan basis entrepreuner ini.

"Pondok Pesantren Al Mumtaz dalam proses pendidikan berbasis entrepreunership ini selalu menanamkan nilai-nilai pendidikan Islam, jadi dalam proses belajar mengajar guru memberikan tauladan yang baik terhadap peserta didik dengan cara mencontohkan terlebih dahulu kemudian memberikan suatu 
4326 Pengembangan Pendidikan Islam Berbasis Entrepreneur pada Pondok Pesantren Al Mumtaz PatukFajrus Shodiq, Nur Khusaini, Bintang Muhammad Nur Ikhsan,Siti Halawatus Sa'diyah, Aulia Faiqotul Himma

DOI: https://doi.org/10.31004/edukatif.v3i6.1447

pengertian yang baik dalam pelaksanaan kewirausahaan, mana yang baik dan benar (Hasil wawancara dengan Denan Heratamtama, 19 Agustus 2020)

Metode Pendidikan Islam Pondok Pesantren al Mumtaz dangan basis Entrepreunership, antara lain:

1. Metode Keteladanan yang Baik

Keteladanan dan pendidikan adalah dua hal yang dibutuhkan dalam mencetak generasi bangsa Indonesia yang baik, berakhlak, bermoral, dan berbudi pekerti. Guru menjadi faktor utama yang dapat mempengaruhi perubahan tingkah laku peserta didik selain dari faktor lingkungan dan faktor keluarga. Adapun metode-metode keteladanan yang dilaksanakan oleh guru, antara lain: Pertama, guru memberikan teladan. Kedua, guru memberikan pembiasan yang baik. Ketiga, guru mendidik melalui kedisiplinan (Hasil wawancara dengan Denan Heratamtama, 19 Agustus 2020)

\section{Metode Pembentukan Karakter Santri}

Dalam kurikulum entrepreunership, adanya penanaman proses pembelajaran dan tata nilai kewirausahaan yang mengedepankan pemeliharaan dan pembiasaan sikap dan perilaku, antara lain: Pertama, Percaya diri (Hamali, 2017: 49). Kedua, Berorientasi tugas dan hasil (Hamali, 2017: 50). Ketiga, Keberanian mengambil resiko. Keempat, Kepemimpinan yang baik.

\section{Menanamkan Nilai-nilai Islam Saat Entrrepreneur}

Dalam mewujudkan karakter kewirausahaan santri pondok pesantren Al Mumtaz menerapkan nilai-nilai pendidikan Islam yang diajarkan demi tercapainya jiwa kewirausahaan yang religius, antara lain: Pertama, nilai pendidikan akidah (Aminuddin, 2006: 1). Kedua, nilai pendidikan syariah (Mohammad Daud Ali, 2016). Ketiga, nilai pendidikan akhlak (Mohammad Daud Ali, 2016: 246)

\section{Metode Praktik Lamgsung Entrepreuner}

Pengembangan pendidikan Islam berbasis entrepreneur pada pondok pesantren Al Mumtaz ini harus menyentuh aspek psikomotorik sehingga santri mampu melakukan secara penuh dengan kesadarannya sendiri. Maka dalam kegiatan pendidikan Islam berbasis entrepreneur ini santri wajib melakukan praktik secara langsung di beberapa unit usaha yang sudah dikembangkan pondok pesantren Al Mumtaz. Adapun Metode Praktik Langsung Entrepreuner, antara lain: Pertama, usaha pertanian. Kedua, usaha perikanan. Ketiga, usaha retail. Keempat, usaha pengisian air ulang. Kelima, usaha bakpia. Keenam, usaha batik (Observasi,19 Agustus 2020)

\section{Dampak Pengembangan Pendidikan Islam Berbasis Entrepreneur}

Berdasarkan observasi dan wawancara peneliti terhadap responden pondok pesantren al-Mumtaz, dampak terhadap santri pondok pesantren Al Mumtaz dari pengembangan pendidikan Islam berbasis Entrepreunership antara lain: Pertama, memiliki keterampilan. Kedua, menumbuhkan jiwa entrepreneur. Ketiga, memberikan pengertian bahwa orang bertasawuf tidak melulu miskin. Keempat, menumbuhkan sikap mandiri. Kelima, membantu kebutuhan pondok (Observasi, 20 Juni 2020)

\section{KESIMPULAN}

Konsep Pendidikan Agama Islam yang di jalankan di Pondok Pesantren Al Mumtaz Patuk Gunung Kidul pada umumnya sama seperti pondok pesantren yang lainnya. Konsep besar dari Pendidikan Islam berbasis entrepreneur yaitu untuk membantu pemerintah memberantas kemiskinan. Dalam kurikulum entrepreuner, proses pembelajaran penanaman tata nilai kewirausahaan mengedepankan pembiasaan dan 
4327 Pengembangan Pendidikan Islam Berbasis Entrepreneur pada Pondok Pesantren Al Mumtaz PatukFajrus Shodiq, Nur Khusaini, Bintang Muhammad Nur Ikhsan,Siti Halawatus Sa'diyah, Aulia Faiqotul Himma

DOI: https://doi.org/10.31004/edukatif.v3i6.1447

pemeliharaan perilaku serta sikap. Seorang wirausahawan harus memiliki sifat sebagai wirausahawan yaitu, percaya diri, berorientasi tugas dan hasil, keberanian mengambil risiko dan kepemimpinan yang baik.

Pondok Pesantren Al Mumtaz dalam proses pendidikan berbasis entrepreunership selalu menanamkan nilai-nilai pendidikan islam, jadi dalam proses belajar mengajar guru memberikan tauladan yang baik terhadap peserta didik dengan cara mencontohkan terlebih dahulu kemudian memberikan suatu pengertian yang baik dalam pelaksanaan kewirausahaan, mana yang baik dan benar. Dalam upaya pengembangan pendidikan Agama Islam Pondok Pesantren Al-Mumtaz menerapkan nilai-nilai Pendidikan Agama Islam yaitu, akidah, syariah, dan akhlak. Sedangkan metode yang digunakan dalam pembentukan Pendidikan Islam berbasis entrepeneur menggunakan metode keteladanan, latihan dan pembiasaan, dan kedislipinan. Bentuk dari upaya pengembangan Pendidikan Agama Islam berbasis Entrepeneur yaitu, usaha batik, pertanian, perikanan, pembuatan bakpia, usaha retail dan usaha pengisian air ulang.

Dampak pengembangan pendidikan Islam berbasis entrepreneurship terhadap santri pondok pesantren Al Mumtaz yaitu: Pertama, Memiliki keterampilan. Kedua, Menumbuhkan jiwa entrepreneur. Ketiga, Memberikan pengertian bahwa orang bertasawuf tidak melulu miskin. Keempat, Menumbuhkan sikap mandiri. Kelima, Membantu kebutuhan pondok

\section{DAFTAR PUSTAKA}

Akhidiyat, Benu Ahmad Saebani Danra Hendra. (2009). Ilmu Pendidikan Islam. Bandung: Cv. Pustaka Setia. Alma, B. (2018). Kewirausahaan. Bandung: Alfabeta.

Aminuddin, D. (2006). Membangun Karakter Dan Kepribadian Melalui Pandidikan Agama Islam. Yogyakarta: Graha Ilmu.

Anwar, S. (1999). Metode Penelitian. Yogyakarta: Pustaka Pelajar.

Aziz, N. B. Dan E. (2014). Etika Islam Dalam Berbisnis. Yogyakarta: Pustaka Belajar.

Beni Ahmad Saebani Dan Hendra Ahdiyat. (2012). Ilmu Pendidikan Islam. Jawa Barat: Cv. Pustaka Setia.

Hamali, A. Y. (2017). Pemahaman Kewirausahaan. Depok: Kencana. Diambil Dari Https://Books.Google.Com/Books?Hl=En\&Lr=\&Id=Moc2dwaaqbaj\&Oi=Fnd\&Pg=Pp1\&Dq=Pengertian +Wirausaha\&Ots=Qlb_Gkscjj\&Sig=B2tpdeynp7o767gnprmdpw1zjhu

Hasan, A. (2013). Manejemen Bisnis Syari'ah. Yogyakarta: Pustaka Belajar.

Komariah, D. S. Dan A. (2011). Metodologi Penelitian Kualitatif. Bandung: Alfabeta.

Marthon, S. S. (2004). Ekonomi Islam Di Tengah Krisis Global. Jakarta: Zikrul Hakim.

Masduki Hs, M. (2002). Pendidikan Pesantren Antara Normativitas Dan Objektivitas, Majalah Pesantren. Majalah Pesantren: Lakpesdam Nu Edisi I/Th.1/.

Meilani, K. S. (2017). Manajemen Pendidikan Entrepreneurship Bagi Siswa Smp Negeri 4 Banyumas. Skripsi, Instituut Agama Islam Negeri Purwokerto.

Mohammad Daud Ali. (2016). Pendidikan Agama Islam. Jakarta: Raja Wali Pers.

Moloeng, L. J. (2012). Metode Penelitian Kualitatif. Bandung: Pt. Remaja Rosdakarya.

Noor, M. (2006). Potret Dunia Pesantren. Bandung: Humonior.

Patmawati, E. (2017). Pelaksanaan Program Pendidikan Islamic Entrepreneur Di Boarding School Man 2 Surakarta Tahun Pelajaran 2016/2017.

Qodry, A. (2004). Melawan Globalisasi Reinterprestasi Ajaran Islam. Yogyakarta: Pustaka Belajar. 
4328 Pengembangan Pendidikan Islam Berbasis Entrepreneur pada Pondok Pesantren Al Mumtaz PatukFajrus Shodiq, Nur Khusaini, Bintang Muhammad Nur Ikhsan,Siti Halawatus Sa'diyah, Aulia Faiqotul Himma

DOI: https://doi.org/10.31004/edukatif.v3i6.1447

Sugiyono. (2013). Metode Penelitian Kuantitatif Kualitatif Dan $R \&$ D. Bandung: Alfabeta.

Syaodih, I. Dan N. (1996). Perencanaan Pengajaran. Jakarta: Rineka Cipta.

Widiyanti, A. (2012). Integrasi Pendidikan Entrepreneurship Pada Mata Pelajaran Fiqih Dalam Meningkatkan Life Skill Siswi Kelas X Madrasah Aliyah Mu'allimaat Muhammadiyah Yogyakarta Tahun Ajaran 2011/2012. 